\title{
Integrin av $\beta 5$ is a primary receptor for adenovirus in CAR-negative cells
}

\author{
Cynthia Lyle* and Frank McCormick
}

\begin{abstract}
Background: Viruses bind to specific cellular receptors in order to infect their hosts. The specific receptors a virus uses are important factors in determining host range, cellular tropism, and pathogenesis. For adenovirus, the existing model of entry requires two receptor interactions. First, the viral fiber protein binds Coxsackie and Adenovirus Receptor (CAR), its primary cellular receptor, which docks the virus to the cell surface. Next, viral penton base engages cellular integrins, coreceptors thought to be required exclusively for internalization and not contributing to binding. However, a number of studies reporting data which conflicts with this simple model have been published. These observations have led us to question the proposed two-step model for adenovirus infection.
\end{abstract}

Results: In this study we report that cells which express little to no CAR can be efficiently transduced by adenovirus. Using competition experiments between whole virus and soluble viral fiber protein or integrin blocking peptides, we show virus binding is not dependent on fiber binding to cells but rather on penton base binding cellular integrins. Further, we find that binding to low CAR expressing cells is inhibited specifically by a blocking antibody to integrin $\operatorname{av} \beta 5$, demonstrating that in these cells integrin av $\beta 5$ and not CAR is required for adenovirus attachment. The binding mediated by integrin av $\beta 5$ is extremely high affinity, in the picomolar range.

Conclusions: Our data further challenges the model of adenovirus infection in which binding to primary receptor CAR is required in order for subsequent interactions between adenovirus and integrins to initiate viral entry. In low CAR cells, binding occurs through integrin av $\beta 5$, a receptor previously thought to be used exclusively in internalization. We show for the first time that integrin av $\beta 5$ can be used as an alternate binding receptor.

\section{Background}

Viruses bind to specific cellular receptors to infect their hosts. The specific receptors a virus uses are important factors in determining host range, cellular tropism, and pathogenesis. HIV-1 is one of the best characterized viruses in terms of viral entry. HIV-1 first binds to CD4, its primary receptor $[1,2]$. Although $\mathrm{CD} 4$ binding was initially thought to be sufficient for infection, it was later found that a second interaction between HIV and chemokine co-receptors CCR5 or CXCR4, is also required [3-5]. Binding to $\mathrm{CD} 4$ occurs first, triggering conformational changes in the HIV protein gp120, revealing the previously hidden binding site for its coreceptors, which then trigger membrane fusion [6,7]. The discovery of HIV's requirement for co-receptors in addi-

* Correspondence: cynthia.l.lyle@gmail.com

1 UCSF Helen Diller Family Comprehensive Cancer Center, University of California, San Francisco, San Francisco, CA, 94158, USA

Full list of author information is available at the end of the article tion to CD4 represented a significant shift in our understanding of viral entry. The idea that a single virus bound to a single entry receptor was replaced with the idea that viral entry is the result of distinct sequential events requiring multiple surface proteins.

In keeping with this multistep entry model, adenoviruses have been proposed to use a primary receptor to mediate binding and co-receptors to mediate internalization [8]. Adenoviruses are non-enveloped double stranded DNA viruses associated with respiratory disease, ocular disease, and gastroenteritis [9]. Adenoviruses have three major capsid proteins: hexon, which forms the bulk of the capsid and is present in 240 copies, penton base, which is present in five copies at each of the twelve vertices, and fiber, a homotrimeric protein that protrudes from each vertice, extending outward from the penton base. More than 50 human serotypes of adenovirus have been identified to date $[10,11]$. The best studied of these are the species $\mathrm{C}$ adenoviruses, including Adenovirus 
Serotype 2 (Ad2) and Adenovirus Serotype 5 (Ad5). The primary receptor for species $C$ adenoviruses is thought to be Coxsackie and Adenovirus Receptor (CAR), which binds to the globular knob domain of fiber [12]. This high affinity interaction docks the virus to the cell, thus allowing secondary interactions to occur. Following fiber binding to CAR, the penton base engages $\alpha v \beta 3$ and $\alpha v \beta 5$ integrins to initiate endocytosis and viral entry [8]. Adenoviruses bind to integrins via an RGD motif present in the penton base. The penton base-integrin interaction is proposed to be exclusively involved in virus internalization and not to contribute to virus binding [8].

Several studies have reported alternate mechanisms for adenovirus entry. Huang et al demonstrated that adenovirus binds to hematopoietic cells via a penton base interaction with Integrin $\alpha M \beta 2$, an integrin not expressed on epithelial cells, but still requires $\alpha v$ integrins for virus internalization [13]. Additionally, Ad5 has also been proposed to use heparan sulphate glycosaminoglycans as receptors [14,15] and to use lactoferrin as a bridge between viral particles and the cell surface [16,17]. In both of these systems, adenovirus fiber is the viral protein required for binding. Further complication is observed in vivo. Infection of liver cells, which has been well characterized, is CAR-independent and instead depends on adenovirus hexon binding the blood coagulation factor $\mathrm{F}(\mathrm{X})$ which leads to infection [18-24]. Additionally, in both mice and non-human primates, adenoviruses with mutant fibers ablated for CAR binding show a similar biodistribution compared to wild type viruses $[18,21,25,26]$. Similarly, a lack of correlation between CAR expression and adenovirus infection has been observed in cell lines, though the mechanism by which infection of cells with low CAR is achieved is undefined $[12,27,28]$.

We also observe a lack of correlation between CAR expression and infection in cell lines. Indeed, we report here that an Ad5 vector can efficiently transduce cancer cells which express little to no CAR. Further, Ad5 binds to these cells via integrin $\alpha v \beta 5$, a surface protein previously thought to be used exclusively for internalization and thus classified as a secondary co-receptor. These observations lead us to further question the two-step model for adenovirus infection, in which adenovirus must first bind to CAR, the primary receptor, in order to bind to integrins and trigger viral entry.

\section{Results}

\section{Adenovirus infection is variable across a panel of cancer} cell lines

Although alternate entry routes have been described, the best characterized model of adenovirus entry requires binding of adenovirus fiber to the cellular membrane protein CAR to initiate infection [12]. CAR is a cell adhesion molecule and, like other cell adhesion molecules, is down-regulated during cancer progression [29-34]. Several reports have shown that the ability of adenoviruses to infect different cancer cell lines is variable [31,33-36]. Therefore, we chose a panel of cancer cell lines, consisting of human melanoma cells and human breast cancer cells, to study the requirement for a CAR-mediated binding event in adenovirus infection. We first measured the ability of Ad5 to infect this panel of cancer cell lines. Cells were infected with a non-replicating virus deleted for E1A that expresses GFP (Ad5-GFP) and GFP expression was used as a measure of transduction. Cells were infected at a multiplicity of infection (MOI) 25 because at this MOI cells show a high level of transduction but the system is not saturated (Additional File 1). Figure 1 shows that at MOI 25, Ad5-GFP transduced these cells with a wide range of efficiency. The percentage of cells positive for GFP as well as the mean fluorescence intensity (MFI) for each cell line is displayed in Table 1. SkMel2 cells were most infectible with $97 \%$ of cells positive for GFP. MDAMB-435, MCF7, MDA-MB-231, and MDA-MB-453 cells were infected at an intermediate level, ranging from 58$79 \%$ of cells GFP-positive. On the lower end of the spectrum, Ad5-GFP infected only about $40 \%$ of both BT549 and WM278 cells. Finally, T47D cells show a very small shift in fluorescence after infection, indicating these cells are resistant to Ad5 infection.

Table 1: Quantification of Ad5 transduction and CAR expression across the panel of cell lines

\begin{tabular}{lcccc}
\hline & \multicolumn{2}{c}{ Transduction } & \multicolumn{2}{c}{ CAR Expression } \\
\hline Cell Line & \% positive & MFI & \% positive & MFI \\
\hline SkMel2 & 97.1 & 575 & 98.3 & 68.3 \\
\hline MDA-MB-231 & 69.3 & 438 & 93.5 & 31.2 \\
\hline BT549 & 35.5 & 86.2 & 42.2 & 12.6 \\
\hline MDA-MB-453 & 58.1 & 78.3 & 98.1 & 40 \\
\hline MDA-MB-435 & 79.2 & 657 & 0.5 & 3.9 \\
\hline MCF7 & 67 & 673 & 2.9 & 4.9 \\
\hline WM278 & 45.9 & 186 & 2.8 & 12.6 \\
\hline T47D & 13.6 & 50.6 & 71.8 & 32.2 \\
\hline
\end{tabular}

Quantification of data displayed in Figure 1 (Transduction) and Figure 2a (CAR expression). MFI is mean fluorescence intensity. 

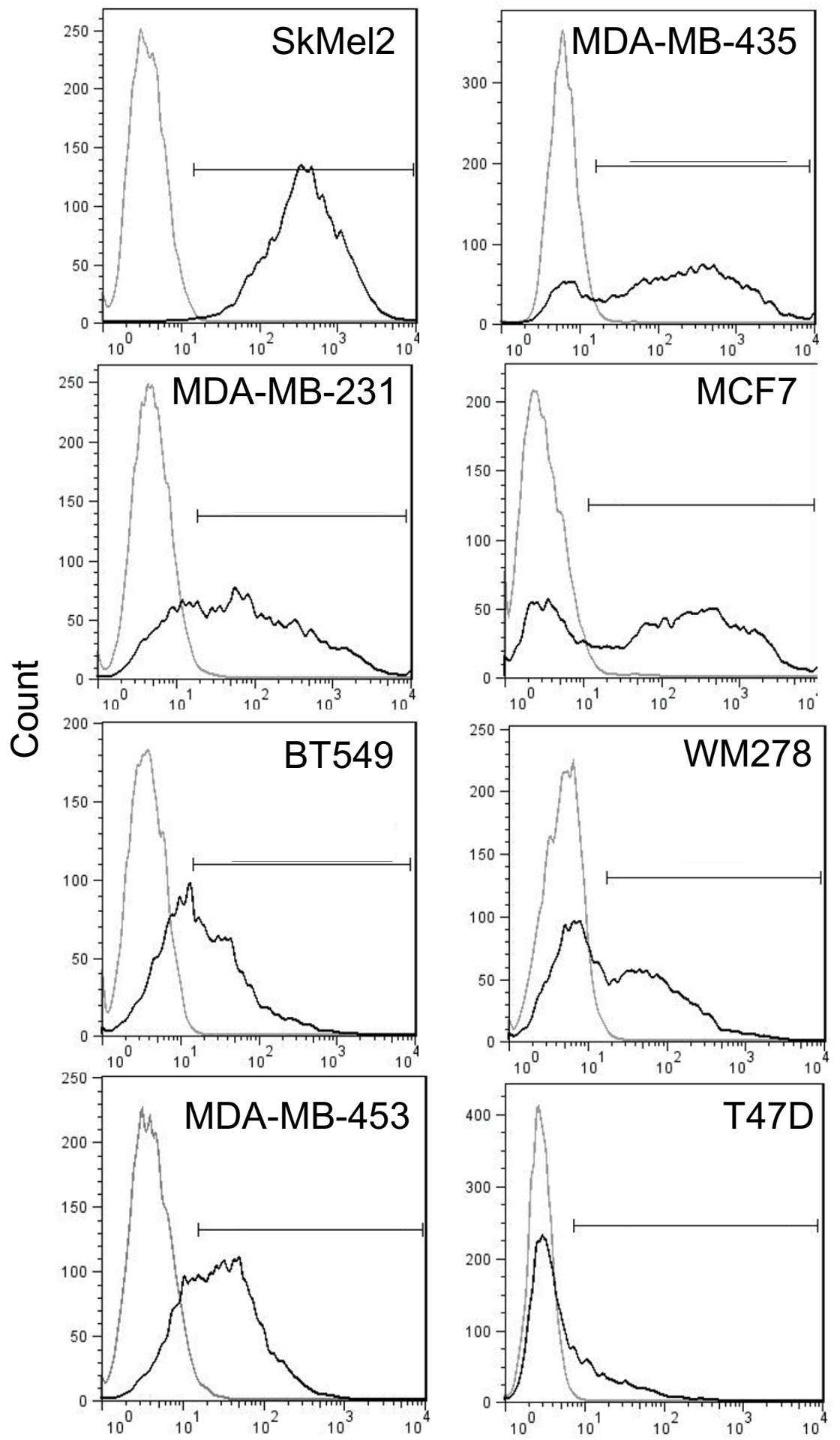

Fluorescence

Figure 1 Ad5 transduction is variable across a panel of cancer cell lines. Cells were infected with Ad5-GFP at MOI (PFU/cell) 25 and incubated overnight. Infection was quantified immediately following the overnight incubation using flow cytometry analysis of cells infected with Ad5-GFP (black line) compared to an uninfected control (grey line) for each cell line. 10000 events were acquired and live cells were gated before assessing fluorescence. The percentage of cells positive for GFP is quantified as well as the mean fluorescence intensity (MFI) in Table 1. Data shown is representative of at least two independent experiments. 


\section{Surface CAR levels do not explain differences in Ad5 entry}

CAR expression is a primary determinant for Ad5 entry. To investigate whether the variability in transduction could be explained by differences in CAR levels, we next measured surface CAR expression using flow cytometry. Figure 2a shows that most of the cell lines, including SkMel2, MDA-MB-231, MDA-MB-453 and T47D cells, express CAR on the majority of cells. Interestingly, T47D cells, which are resistant to Ad5 infection, also express CAR on the cell surface. In contrast, WM278, MDA-MB435, and MCF7 cells, all of which are infectible with Ad5GFP, express little to no CAR on the cell surface. Quantification of both the percentage of cells positive for CAR expression as well as the MFI is displayed in Table 1. These data suggests CAR binding is neither sufficient nor necessary for Ad5 entry.

We next verified CAR expression by measuring mRNA levels in two high CAR and two low CAR cell lines using TaqMan analysis. Figure $2 b$ shows that CAR mRNA levels correlated with surface protein levels (Figure 2b). The two cell lines (MDA-MB-435, and MCF7) which show litthe to no surface CAR expression also had very little to, in the case of MDA-MB-435 cells, no detectable CAR mRNA expressed (Figure $2 \mathrm{~b}$ ).

\section{Infection of CAR-negative cells is fiber-independent}

Previous reports have indicated that the fiber-CAR interaction mediates binding of Ad5 to the cell surface $[8,12,37]$. Additionally, Ad5 fiber has been reported to bind cells through heparin sulphate proteoglycans or through a lactoferrin bridge [14-17]. Therefore, we next examined whether Ad5 infection, although not dependent on CAR, is still dependent on fiber, perhaps by binding to a different cellular receptor. To address this question, we tested the dependence of infection in low CAR cells on fiber. Cells were preincubated with soluble fiber prior to adding Ad5-GFP to the cells and measuring transduction, as determined by GFP expression. Transduction of MDA-MB-231 and SkMel2 cells, both of which express CAR (Figure 2), could be blocked in a dose-dependent manner by preincubation with soluble fiber (Figure 3). In contrast, transduction of low CAR cells MCF7 and MDA-MB-435 was not blocked. Ad5 infection of MCF7 and MDA-MB-435 cells is therefore not only CAR-independent but also fiber-independent. Interestingly, at the highest concentration, preincubation with fiber actually increases transduction in MCF7 cells.

\section{Binding to CAR-negative cells is integrin-dependent}

Our fiber blocking studies ruled out the possibility that fiber binds an alternate receptor in CAR-negative cells. A second well-characterized interaction between Ad5 and the cell surface is the binding of the RGD (Arg-Gly-Asp) domain in the penton base of adenovirus to integrin $\alpha v \beta 3$ and integrin $\alpha v \beta 5$ [8]. Integrins are heterodimeric cell surface molecules that mediate cell-extracellular matrix and cell-cell interactions and are therefore involved in a number of cellular processes [38]. Additionally, several viruses and bacteria have been reported to use integrins to enter host cells [39-42]. Integrin-mediated processes are often regulated by both ligand binding and integrin clustering; therefore, many integrin ligands are multivalent, able to bind multiple integrins simultaneously [43]. The crystal structure of the RGD domain of the adenovirus penton base binding integrin $\alpha v \beta 5$ has been resolved, revealing that one penton base complex of the virus binds approximately four integrin molecules [44]. Blocking binding to integrin $\alpha v \beta 5$, as well as $\alpha v \beta 3$, prevents adenovirus from being internalized but does not impact binding of adenovirus to the cell surface [8]. Although these studies predate the discovery of CAR, the cells used in them expressed a fiber receptor, most likely CAR, as infection of the cells could be blocked by soluble fiber [8]. Another study suggests integrin $\alpha 3 \beta 1$ can bind Ad5 to cells, both in the presence and absence of CAR, although the mechanism of this binding is unclear since it apparently is not mediated by the RGD domain of Ad5 penton base [45]. Additionally, Huang et al observed that in hematopoietic cells lacking CAR, binding to the cell surface is mediated by the leukocyte integrin $\alpha M \beta 2$ [13]. Therefore, we sought to identify what role integrins play in the infection of these low CAR cancer cells. To distinguish between two possibilities, binding and internalization, we used an assay to directly measure binding. Cells were plated in 96-well plates and incubated overnight at $37^{\circ} \mathrm{C}$. Cells were chilled to $4^{\circ} \mathrm{C}$, a temperature which allows binding but does not permit internalization, and then preincubated with increasing concentrations of an integrin-blocking peptide, RGD, or a control peptide, RGE. Ad5 was added to the cells at $4^{\circ} \mathrm{C}$ and incubated for six hours. Cells were washed and fixed and virus bound determined using an antibody directed against Ad5 capsid proteins. Figure 4a shows that in SkMel2 and MDA-MB-231 cells, which express CAR, integrin blocking peptide RGD does not block Ad5 binding, consistent with previous reports. However, in both MDA-MB-435 and MCF7 cells, which are low CAR, Ad5 binding to cells is blocked by RGD, showing that binding in these cells is integrin-dependent.

$\alpha v \beta 3, \alpha v \beta 5$, and the $\beta 1$ subunithave been specifically implicated in adenovirus infection [8,45-47]. Therefore, we measured the levels of these integrins on the surface of MDA-MB-435 and MCF7 cells, both of which lack CAR expression, as well as SkMel2 and MDA-MB-231 cells, both of which express CAR. We found that MDAMB-435 and SkMel2 cells express all three integrins (Figure $4 \mathrm{~b})$. MCF7 and MDA-MB-231 cells only express $\alpha v \beta 5$ and the $\beta 1$ subunit (Figure $4 \mathrm{~b}$ ). The expression levels are 
A
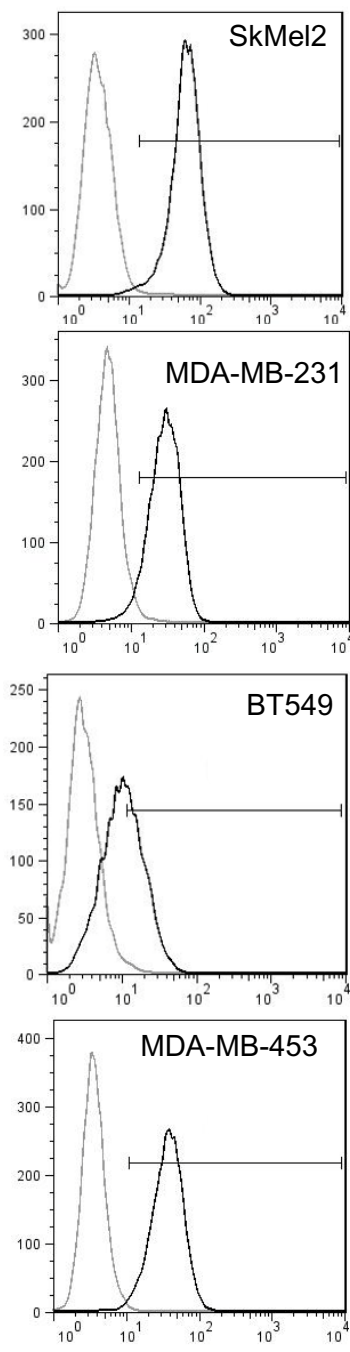
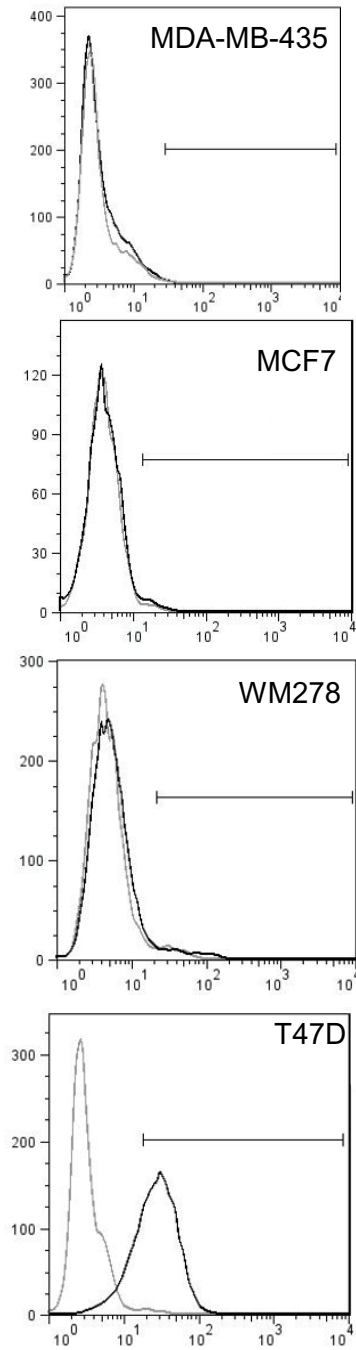

B

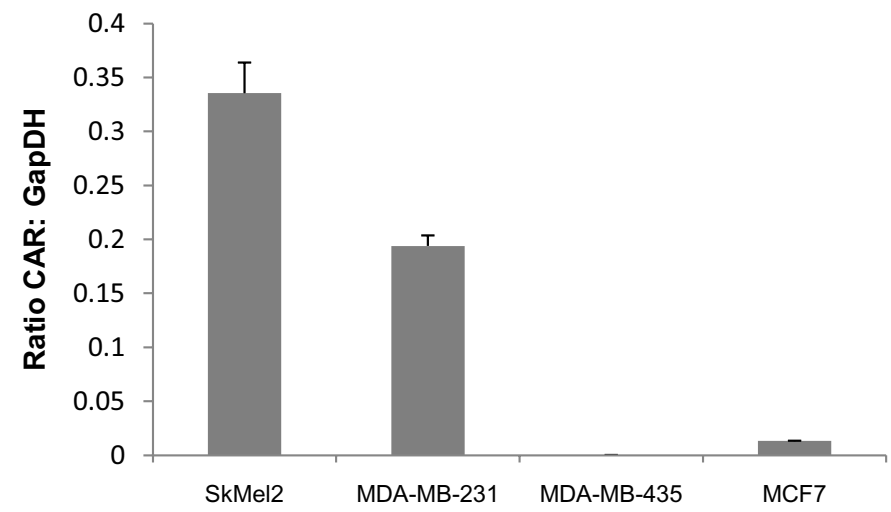

Figure 2 CAR expression levels. (A) Surface CAR levels were detected using flow cytometry. Cells were stained either with the monoclonal antibody RmcB which recognizes CAR (black line) or for control, only the secondary antibody, goat anti-mouse Alexa 488(grey line). The secondary only population was set to approximately $1 \%$ positive and used as the negative population for each cell line. The percentage of cells which are positive for CAR as well as the MFI is quantified and displayed in Table 1. Data shown is representative of at least two independent experiments. (B) CAR mRNA levels were determined using quantitative real-time PCR. CAR mRNA levels are compared to the control gene GapDH and data is presented as a ratio of CAR: $\mathrm{GapDH}$. Data is the average of at least two independent experiments and error bars represent standard deviation. 


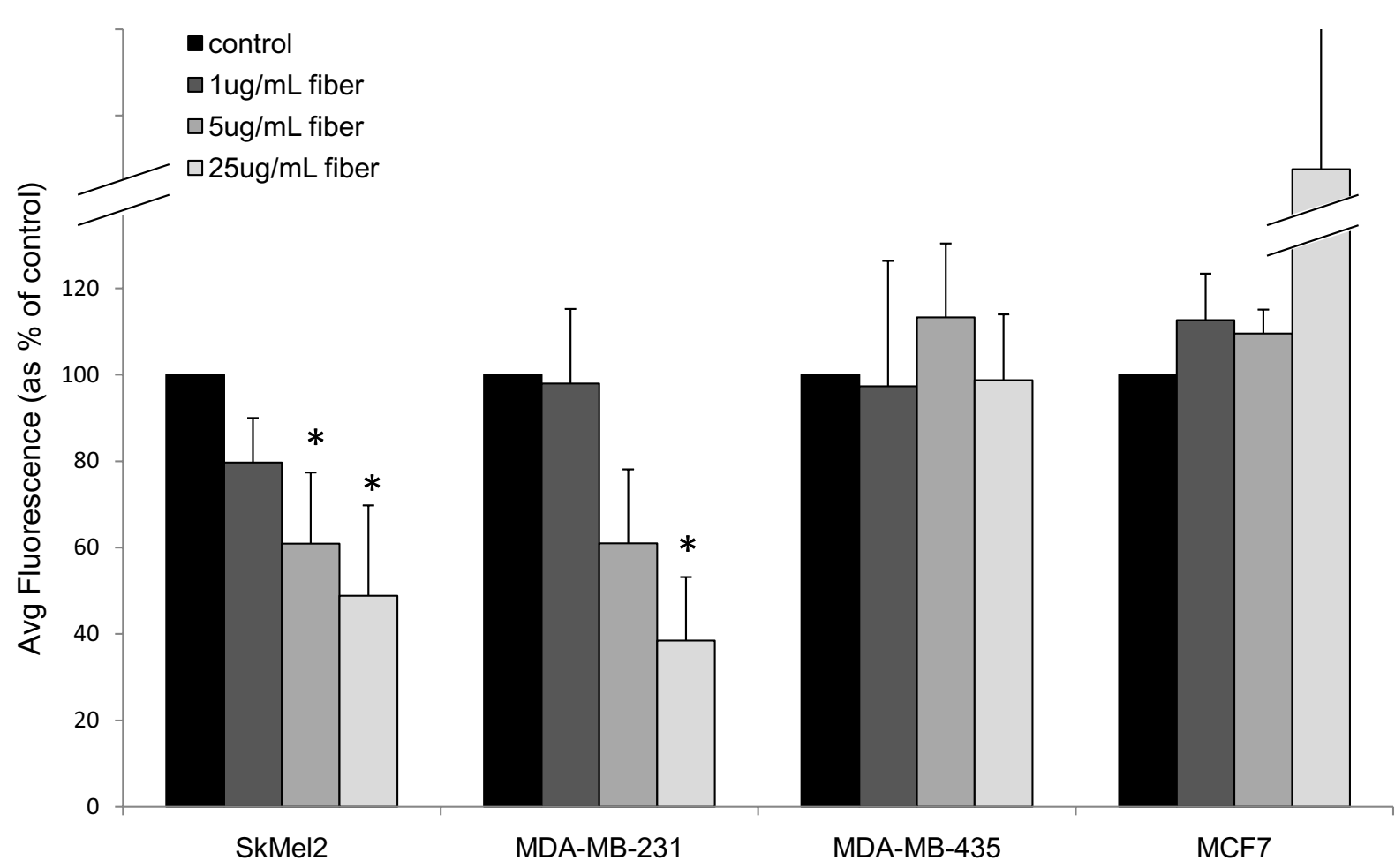

High CAR

Low CAR

Figure 3 Infection low CAR cells is fiber-independent. Cells were preincubated for $1 \mathrm{hr}$ with increasing concentrations of soluble fiber followed by addition of Ad5-GFP and further incubation overnight. Flow cytometry was used to quantify fluorescence intensity. Data shown is the average of at least three independent experiments and error bars represent standard deviation. ${ }^{*}$ indicates statistical significance, $p \leq 0.05$.

quantified both by percentage of cells staining positive and by MFI in Table 2 .

Next, we investigated whether one of these integrins is responsible for the binding of Ad5 to low CAR cells. Again at $4^{\circ} \mathrm{C}$ to prevent virus internalization, cells were preincubated with antibodies that block ligand binding to integrins and then Ad5 was added to cells and the amount of virus bound measured. Preincubation with blocking antibodies to $\beta 1$ or to $\alpha v \beta 3$, in either MDA-MB435 or MCF7 cells, did not inhibit infection by very much. However, blocking $\alpha v \beta 5$ dramatically reduced Ad5 binding in both cell lines. In MDA-MB-435 cells, blocking $\alpha v \beta 5$ reduced binding to only $5 \%$ of control and in MCF7 cells, binding is reduced to $19 \%$ of control (Figure 4c). From this result, we conclude that binding of Ad5 to low CAR cells occurs via the RGD domain of penton base binding to integrin $\alpha v \beta 5$.

\section{Binding of Ad5 via integrin av $\beta 5$ to CAR-negative cells is high affinity}

To further characterize the interaction between Ad5 and the surface of cells in which binding occurs via integrin $\alpha v \beta 5$, we measured the binding affinity of whole Ad5 and the surface of MDA-MB-435 cells, which bind Ad5 through integrin $\alpha v \beta 5$ (Figure 4c). Figure 5a shows binding to MDA-MB- 435 cells is specific and saturable and represents a typical binding isotherm. To determine the dissociation constant $\left(\mathrm{K}_{\mathrm{d}}\right)$, a measure of the strength of an interaction, we fit the data to the Langmuir binding isotherm (Eqn 1) [48].

$$
\mathrm{Y}=\frac{[L]}{(k d+[L])}
$$

Here, $\mathrm{Y}$ is the fractional occupancy of the receptor and $[\mathrm{L}]$ is the ligand concentration. We performed a non-linear least-squared analysis using MS Excel's Solver function to calculate the $K_{d}$. Figure $5 b$ shows observed versus calculated values of $Y$, demonstrating the observed values fit this equation. We calculate a $\mathrm{K}_{\mathrm{D}}$ of $1.4 \times 10^{-10} \mathrm{M}$. Therefore, we conclude that Ad5 can bind to cells via integrin $\alpha v \beta 5$ and this interaction is high affinity, in the picomolar range. Since previous studies have demon- 
A

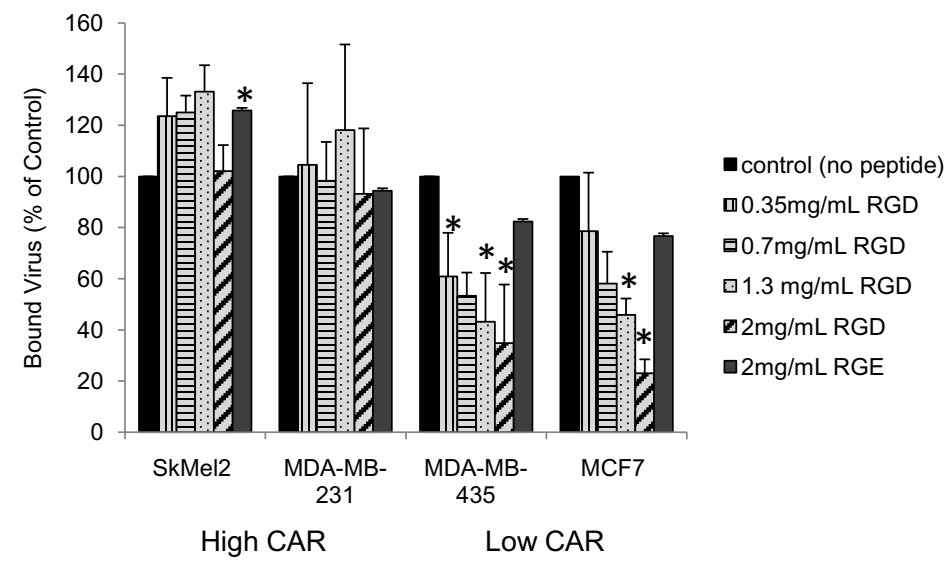

B
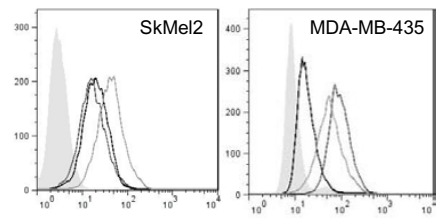

- Integrin $a v \beta 3$

- Integrin $\alpha v \beta 5$

口Integrin $\beta 1$ (unfilled line)

$\square$ Secondary only control (filled line)

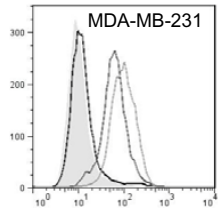

High CAR

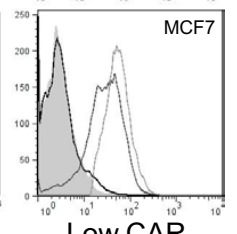

Low CAR

C

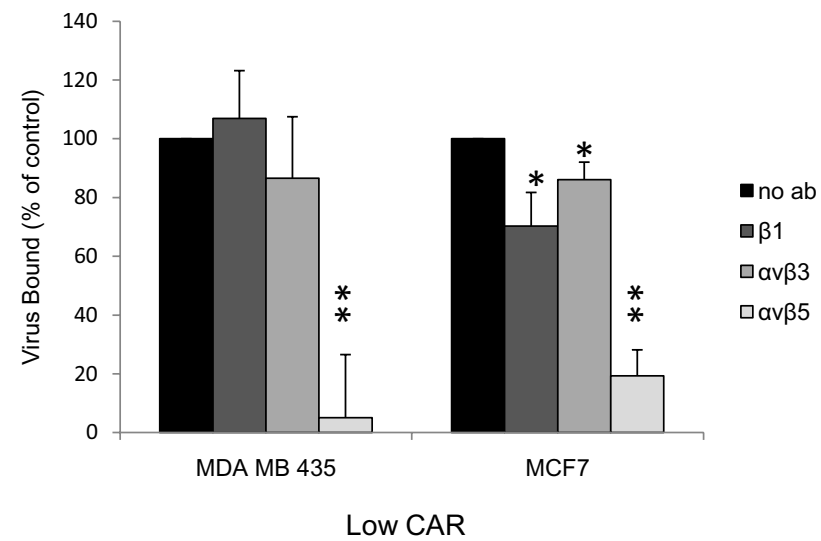

Figure 4 The role of integrins in infection of low CAR cells. (A) Cells were preincubated with media alone, increasing concentrations of synthetic peptide GRGDSP, or control peptide GRGESP for $1 \mathrm{hr}$ followed by the addition of Ad5, all at $4^{\circ} \mathrm{C}$ for $6 \mathrm{hrs}$. Samples were then washed and fixed and virus bound was detected using an ELISA binding assay with an antibody to Ad5 as described in materials and methods. Data shown is the average of at least three independent experiments and error bars represent standard deviation. ${ }^{*}$ indicates statistical significance, $p \leq 0.05$. (B) Surface integrin levels were determined using flow cytometry. Cells were stained with LM609 (integrin av $\beta 3$ ), P1F6 (integrin av $\beta 5$ ), JB1A (integrin $\beta 1$ ), or secondary only control, goat anti-mouse Alexa 488. The secondary only population was set to approximately $1 \%$ positive and used as the negative population for each cell line. The percentage of cells which are positive for each integrin as well as the MFI is quantified and displayed in Table 2. Data shown is representative of at least two independent experiments. (C) Cells were preincubated with media alone or the blocking antibodies LM609, P1F6, OR JB1A for $1 \mathrm{hr}$ followed by the addition of Ad5, all at $4^{\circ} \mathrm{C}$. Virus bound was determined as described in (A). Data shown is the average of at least three independent experiments and error bars represent standard deviation. * indicates statistical significance, $\mathrm{p} \leq 0.05$; ** indicates statistical significance, $p \leq 0.01$. 
Table 2: Quantification of Integrins expression across panel of cell lines

\begin{tabular}{|c|c|c|c|c|c|c|}
\hline \multirow[b]{2}{*}{ Cell Line } & \multicolumn{2}{|c|}{$\alpha V \beta 3$ expression } & \multicolumn{2}{|c|}{$\alpha \mathrm{V} \beta 5$ expression } & \multicolumn{2}{|c|}{$\beta 1$ expression } \\
\hline & $\%$ positive & MFI & $\%$ positive & MFI & $\%$ positive & MFI \\
\hline SkMel2 & 79.5 & 28 & 69.9 & 26.6 & 99 & 52.8 \\
\hline MDA-MB-231 & 6.06 & 177 & 74.8 & 94.2 & 92.2 & 120 \\
\hline MDA-MB-435 & 6.28 & 107 & 94.8 & 110 & 99.4 & 68.3 \\
\hline MCF7 & 4.5 & 32.2 & 75.9 & 48.4 & 84.3 & 63.9 \\
\hline
\end{tabular}

strated that one penton base can bind approximately 4 integrins, the multivalent nature of the penton base integrin interaction likely contributes to the high affinity observed [44].

\section{Discussion}

In this study we report that cells which do not express CAR can be efficiently transduced by Ad5. Adenovirus entry is not dependent on fiber binding to cells but instead is blocked by an RGD peptide that interferes with the RGD domain on the adenovirus penton base binding cellular integrins. Further, we find that binding to low CAR cells is inhibited specifically by a blocking antibody to integrin $\alpha v \beta 5$, demonstrating that integrin $\alpha v \beta 5$ is required for Ad5 attachment to these cells. The binding mediated by integrin $\alpha v \beta 5$ is extremely high affinity, in the picomolar range. Our data further challenges the prevailing model of adenovirus infection, in which binding to a primary receptor, CAR, is required in order for subsequent interactions between adenovirus and integrins to initiate viral entry.

Ad5 binding to low CAR cells is independent of fiber and instead depends on an interaction with integrin $\alpha v \beta 5$. Therefore, Ad5 does not require an independent binding receptor to dock it to the cell before it can interact with internalization receptors. Other viruses are also reported to use both primary binding and internalization receptors. HIV-1 first binds to CD4 followed by binding to the chemokine receptors CCR5 or CXCR4, which trigger membrane fusion [49]. Binding to CD4 induces conformational changes in the HIV protein gp120, revealing the previously hidden binding site for its coreceptors [6]. Variants with mutations in gp120 allowing for direct interaction with coreceptors have been isolated in vitro; however, these variants are sensitive to neutralizing antibodies and therefore selected against in vivo [50]. Therefore, the role of CD4 binding in HIV-1 infection may be particularly critical in evading the immune system of the host.

Unlike HIV-1 binding to CD4, Ad5 binding to CAR does not induce conformational changes in viral proteins, thus facilitating subsequent entry steps [51]. Rather, CAR is thought to facilitate a high affinity interaction to fiber, thus docking the virus to the cell surface and allowing the subsequent interaction between the penton base and integrins to initiate internalization. Indeed, only the extracellular domain of CAR is required for CAR-mediated adenovirus entry [52]. However, previous studies have observed CAR-independent infection and the work in this paper demonstrates that Ad5 can bind directly to integrin $\alpha \mathrm{v} \beta 5$, previously identified as an internalization receptor $[13,14,17,22,45]$. Therefore, our results and the results of others suggest this initial binding step is not required for entry. Nevertheless, CAR binding is conserved in a number of adenovirus serotypes and the fiberCAR interaction is one that is well characterized and is itself of high affinity $[10,53]$. Therefore, CAR binding clearly plays an important role in the adenovirus infection cycle. One possibility is that, even when CAR is not needed to enter cells, CAR functions as an exit receptor [54]. Walters et al report that when Ad5 lyses a cell, excess fiber is released and through binding to CAR, disrupts neighboring cell-cell junctions, allowing for release of the virus back to the apical surface where it may continue infecting cells [54]. Additionally, recent work has demonstrated that adenovirus binding to CAR may induce downstream signaling events that increase integrin activation, thus promoting infection[55]. Therefore, binding to CAR may facilitate entry in ways beyond simply docking the virus to the cell surface. Indeed, at least two serotypes of adenovirus, Ad9 and Ad37, have fibers which bind CAR but do not use CAR as an attachment receptor, supporting the idea that CAR binding is important for steps other than attachment $[10,56]$. Further, it is 
A

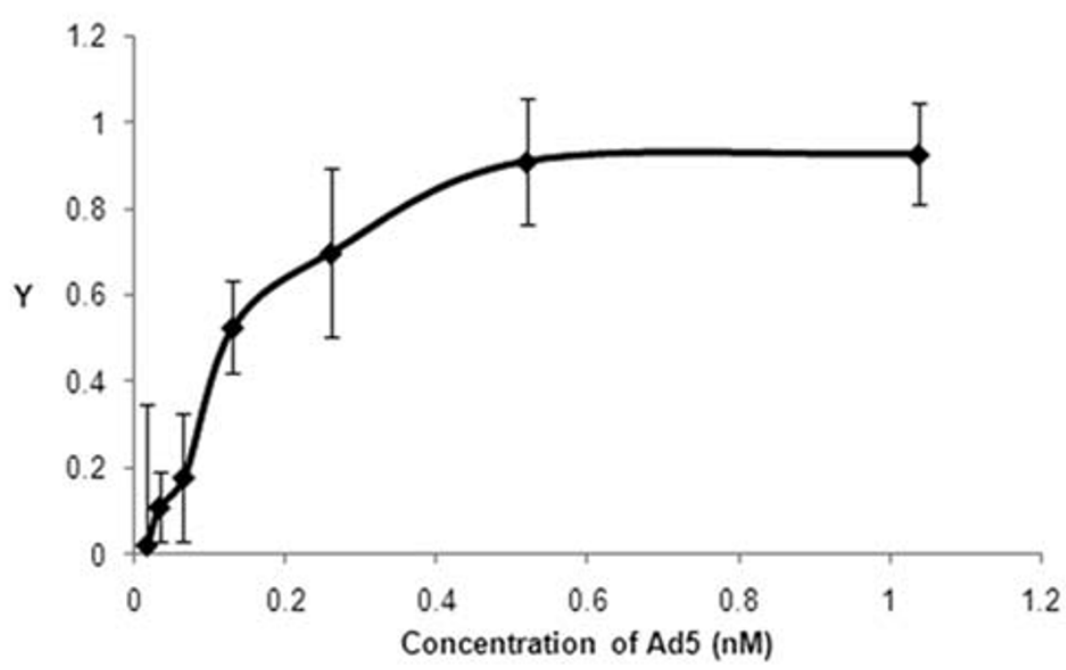

B

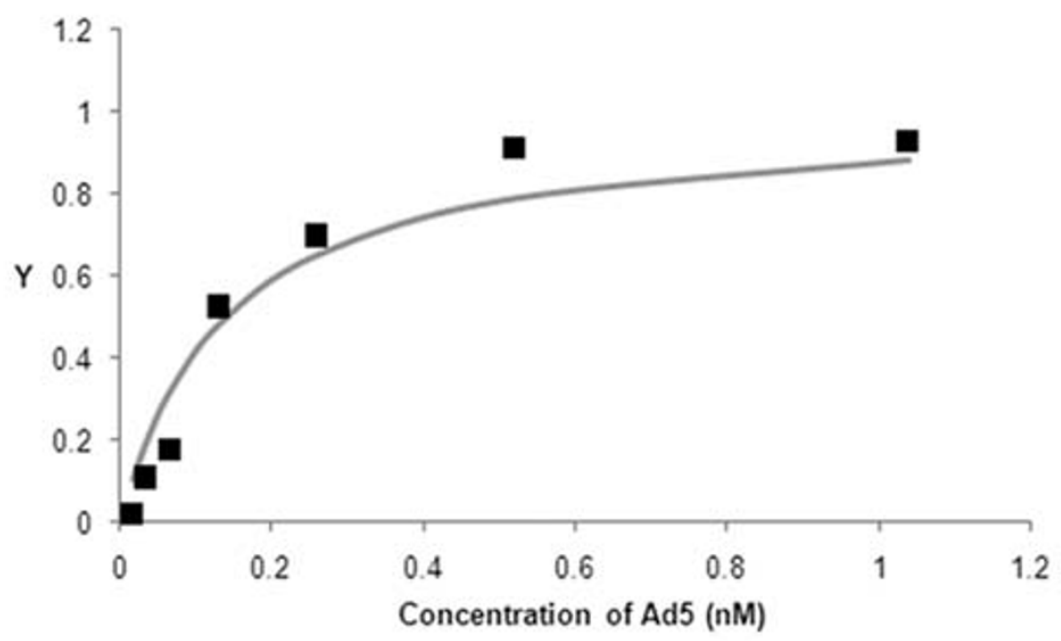

Figure 5 Ad5 binding to cells via integrin av $\beta 5$ is high affinity. (A) Cells were incubated with various concentrations of Ad5 at $4^{\circ} \mathrm{C}$ for sufficient time for virus bound to reach equilibrium. Virus bound was measured as described in Figure 4. Y is the fractional occupancy, which is a ratio of virus bound to maximum virus bound. Data shown is the average of at least three independent experiments and error bars represent standard deviation. (B) Observed data (diamonds) was fit to calculated values (line) using the Langmuir Binding Isotherm (Eqn 1). $K_{d}$ was determined by Microsoft Excel's Solver function using non-linear regression analysis to solve Eqn 1. A $\mathrm{K}_{\mathrm{d}}$ of $1.4 \times 10^{-10} \mathrm{M}$ was calculated from the observed values.

likely advantageous to the virus to be able to use multiple entry routes, enabled by its ability to engage multiple different receptors.

Both HIV, as evidenced by CD4-independent variants isolated in vitro, and Ad5, as evidenced by our results and the results of others can infect cells without binding to their so-called primary receptors. Binding to these receptors, instead of being strictly required for infection, may contribute to other necessary parts of the virus infection cycle, such as evading the host immune system or facili- tating virus escape. Many other viruses with less characterized receptors seem to also use multiple receptors, some classified as binding receptors [57]. For example, rotaviruses are thought to first bind to a sialic acid (SA)containing molecule, which anchors the virus to the cell, and then bind to coreceptors to initiate viral entry [57]. Mutant variants of rotaviruses that are SA-independent and interact directly with coreceptors have been isolated in vitro, suggesting that similarly to HIV and Ad5, binding to the primary receptor is not strictly required for 
infection [58,59]. Therefore, the interaction between rotaviruses and SA-containing molecules may facilitate an as yet unidentified aspect of rotavirus infection. As more functional roles of virus receptors in infection are elucidated, the use of binding receptors in other aspects of the viral life cycle may emerge as a general principle of viral pathogenesis.

In addition to being used as a model system for viral entry, much effort has been put into developing adenoviruses, especially species C adenoviruses including Ad5, as vectors for gene therapy. In fact, adenoviral vectors have been used in more than one quarter of gene therapy trials worldwide [60]. Cancer is one of the most common targets of adenovirus-mediated gene therapy. As mentioned previously, CAR expression is often lost as cancers progress and this loss has been viewed as a major hurdle to using adenovirus-based therapies in cancer [31,33-36]. However, integrin $\alpha v \beta 5$ has been reported to be overexpressed in cancers $[61,62]$. Therefore, our conclusion that Ad5 can use integrin $\alpha v \beta 5$ to bind to and infect cells lacking CAR suggests that cancer cells having lost CAR expression may still be good targets for adenovirus-based therapies. Recent work has shown that erythrocytes sequester adenovirus by binding CAR, thus limiting systemic infection; therefore, using CAR-ablated vectors, a strategy many groups are attempting, may improve delivery for gene therapy for reasons beyond changing receptor interactions $[63,64]$. We also observed what may be an as yet unidentified obstacle to these therapies, however. T47D cells, which express CAR (Figure 2a) and integrin avß5 (data not shown) are still resistant to Ad5 infection (Figure 1). Wang et al showed the cellular protein CEACAM6 blocks adenovirus trafficking to the nucleus in human pancreatic cancer cell lines[65]. Future studies to determine if this protein blocks infection in T47D cells, or if resistance is due to a novel mechanism are needed.

\section{Conclusions}

In conclusion, we have found that cells which express litthe to no CAR can still be efficiently transduced by Ad5. In these cells, CAR is not required: Binding occurs through integrin $\alpha v \beta 5$. We show for the first time that integrin $\alpha v \beta 5$, previously described as an internalization receptor, can also be used as an alternate binding receptor for Ad5.

\section{Methods}

\section{Cell Lines and Viruses}

SkMel2 and WM278 cells are human melanoma cell lines. MCF7, MDA-MB-453, BT549, T47D, MDA-MB-435, and MDA-MB-231 are human breast cancer cell lines. All cells were obtained from the ATCC. SkMel2 cells were cultured in MEM supplemented with sodium pyruvate, non-essential amino acids, and 10\% FBS. WM278 were cultured in DME-H16 and supplemented with 10\% FBS. All other cancer cell lines were cultured in DMEM supplemented with $10 \%$ FBS. Virus used was replication incompetent E1A deleted and expressed GFP (Ad5-GFP). Virus was propagated in HEK293/E4/pIX cells and harvested by $\mathrm{CsCl}$ gradient ultracentrifugation as previously described [66,67]. Virus titers were determined as previously described [68].

\section{Antibodies and Peptides}

The MAb RmcB was used to detect CAR expression [12]. The MAbs LM609, P1F6, and JB1A directed against integrins $\alpha v \beta 3, \alpha v \beta 5$, and the $\beta 1$ subunit respectively were purchased from Chemicon. The secondary antibody Alexa 488 was purchased from Molecular Probes. The synthetic peptides GRGDSP and GRGESP were purchased from Sigma. All antibodies were IgG.

\section{Recombinant Fiber}

Full length Ad5 fiber was cloned from a Gateway entry vector into a his-tagged destination vector using the Gateway system per manufacturer's instructions (Invitrogen). Fiber was transformed into and grown up in BL21 Star (DE3) E.coli (Invitrogen). Overnight starter culture was diluted 1:100 in LB/amp and grown until bacteria reached log phase. 50 uM IPTG was added and bacteria were grown at room temperature overnight. Pellets were disrupted using Bugbuster (Novagen) per manufacturer's instructions. Fiber was purified via its his-tag by incubation with Probond resin (Invitrogen), several washes with $20 \mathrm{mM}$ Imidizole, and elution using Poly-Prep Chromatography Columns (BioRad) with $0.2 \mathrm{M}$ Imidizole. Purified recombinant fiber was then dialyzed into PBS for use in experiments. Approximately $1 \mathrm{mg} / \mathrm{L}$ of purified fiber was obtained.

\section{Cell Infection Assay}

$8 \times 10^{5}$ cells were plated in 6-well plates and incubated overnight at $37^{\circ} \mathrm{C}$. Cells were infected with Ad5-GFP at MOI 25 in DMEM with 2\% FBS. After overnight incubation at $37^{\circ} \mathrm{C}$, cells were trypsinized, washed with PBS, and GFP expression quantitated using flow cytometry. The BD FACSCalibur Flow Cytometer is the instrument used, 10,000 events were acquired for each experiment, gating for live cells, and FlowJo software was used to generate histograms and analyze data. For fiber blocking experiment, prior to addition of Ad5-GFP, different quantities of soluble fiber $(1 \mathrm{ug} / \mathrm{mL}, 5 \mathrm{ug} / \mathrm{mL}$, or $25 \mathrm{ug} / \mathrm{mL})$ were added to cells, incubated at room temperature for $1 \mathrm{hr}$. Then Ad5-GFP was added to cells at MOI 25 and cells were incubated overnight at $37^{\circ} \mathrm{C}$ before flow cytometry analysis. 


\section{Surface expression levels}

Cells were trypsinized, washed with PBS, and $1 \times 10^{6}$ cells were incubated with primary antibody for 30 minutes on ice. Cells were washed, incubated with secondary for 30 minutes on ice, and analyzed by flow cytometry. The BD FACSCalibur Flow Cytometer is the instrument used, 10,000 events were acquired for each experiment, gating for live cells, and FlowJo software was used to generate histograms and analyze data. Dilutions were as follows: RmcB (1-50), LM609 (1-100), P1F6 (1-100), JB1A (1-100), Alexa 488 (1-100). Secondary antibody (Alexa 488) alone was used as a control for each cell line.

\section{Statistics}

Microsoft Excel was used to do a 2 tailed, type $3 \mathrm{~T}$ Test to determine statistical significance.

\section{Quantitative PCR}

Total RNA was isolated from cells using RNeasy Mini Kit (Qiagen). PCR was performed by the Genome Analysis Core Facility, Helen Diller Family Comprehensive Cancer Center, University of California, San Francisco. PCR was conducted in triplicate with $20 \mathrm{uL}$ reaction volumes of $1 \times$ TaqMan buffer (1× Applied Biosystems PCR buffer, 20\% glycerol, $2.5 \%$ gelatin, $60 \mathrm{nM}$ Rox as a passive reference), $5.5 \mathrm{mM} \mathrm{MgCl} 2,0.5 \mathrm{mM}$ each primer, $0.2 \mathrm{uM}$ each deoxynucleotide triphosphate (dNTP), $200 \mathrm{nM}$ probe, and 0.025 unit/uL AmpliTaq Gold (Applied Biosystems) with $5 \mathrm{ng}$ cDNA. A large master mix of the above-mentioned components (minus the primers, probe, and cDNA) was made for each experiment and aliquoted into individual tubes, one for each cDNA sample. cDNA was then added to the aliquoted master mix. The master mix with cDNA was aliquoted into a 384-well plate. The primers and probes were mixed together and added to the master mix and cDNA in the 384-well plate. PCR was conducted on the ABI 7900HT (Applied Biosystems) using the following cycle parameters: 1 cycle of $95^{\circ}$ for 10 minutes and 40 cycles of $95^{\circ}$ for 15 seconds, $60^{\circ}$ for 1 minute. Analysis was carried out using the SDS software (version 2.3) supplied with the ABI 7900HT to determine the Ct values of each reaction. Ct values were determined for three test and three reference reactions in each sample, averaged, and subtracted to obtain the $\Delta \mathrm{Ct}[\Delta \mathrm{Ct}=\mathrm{Ct}$ (test locus) $\mathrm{Ct}$ (control locus)]. PCR efficiencies were measured for all custom assays and were greater than or equal to $90 \%$. Therefore, relative fold difference was calculated for each primer/probe combination as $2^{-\Delta \mathrm{Ct}} \times 100$. PCR primer and TaqMan probe sequences were synthesized by Integrated DNA Technologies (Coralville, IA) [or purchased from Applied Biosystems]. The sequences were as follows

Human CAR

Amplicon:

GGCGCTCCTGCTGTGCTTCGTGCTCCTGTGCG GAGTAGTGGATTTCGCCAGAAGTTTGAGTATCAC TACTCCTGAAGAGATGATTGAAAAAGCCAAAG
Forward: GGCGCTCCTGCTGTGC Reverse: CTTTGGCTTTTTCAATCATCTCTTC Probe: TGCGGAGTAGTGGATTTCGCCAGAAG Human GapDH:

Amplicon: ATTCCACCCATGGCAAATTCCATG GCACCGTCAAGGCTGAGAACGGGAAGCTTGTCA TCAATGGAAATCCCA

Forward: ATTCCACCCATGGCAAATTC

Reverse: TGGGATTTCCATTGATGACAAG

Probe: ATGGCACCGTCAAGGCTGAGAACG

\section{Ad5 Binding Assay}

Cells were plated in 96-well SigmaScreen poly-D-lysine coated plates (Sigma) and incubated overnight at $37^{\circ} \mathrm{C}$. For peptide and antibody blocking experiments, cells were prechilled at $4^{\circ} \mathrm{C}$ for 30 minutes followed by addition of either peptide at indicated concentration or antibody $(500 \mathrm{ug} / \mathrm{mL})$ for $1 \mathrm{hr}$. Ad5-GFP (0.04 ug/uL, protein concentration determined by Bradford assay) diluted in DMEM with 50\% FBS was added to cells and incubated for $6 \mathrm{hrs}$ at $4^{\circ} \mathrm{C}$. Cells were washed several times and fixed with ice cold solution of $95 \% \mathrm{EtOH} / 5 \%$ Acetic Acid. Cells were washed $1 \times$ TBST $(0.05 \mathrm{M}$ Tris, $0.15 \mathrm{M} \mathrm{NaCl}, 0.5 \%$ Tween-20, pH 7.5) and incubated in Superblock (Pierce) for $1 \mathrm{hr}$ at RT. Cells were washed $2 \times$ Superblock followed by incubation with a non-related control IgG antibody to block any non-specific interactions for $30 \mathrm{~min}$, RT. Cells were washed $1 \times$ TBST and incubated with polyclonal rabbit anti-Ad5 antibody (Access Biomedical) for $30 \mathrm{~min}$, RT, followed by washing 4xTBST. Cells were next incubated with Goat-anti-Rabbit-AP (Pierce) for $30 \mathrm{~min}$, RT, followed by washing 4 xTBST. Signal was then amplified and detected using an Elisa Amplification System per manufacturer's instructions (Invitrogen). For determining $K_{D}$ of Ad5 binding to cells, the above protocol was used except cells were incubated with Ad5 at varying concentrations for $18 \mathrm{hrs}$ at $4^{\circ} \mathrm{C}$ prior to fixing

\section{Additional material}

Additional file 1 Dose response of Ad5 infection in a high CAR cell line and a low-CAR cell line. Cells were infected with Ad5-GFP at the indicated $\mathrm{MOI}$ and incubated overnight. Infection was quantified using flow cytometry analysis to quantify infection at each $\mathrm{MOI}$ in each cell line. The mean fluorescence intensity is quantified and displayed in the figure. Data shown is representative of at least two independent experiments.

\section{Competing interests}

The authors declare that they have no competing interests.

\section{Authors' contributions}

$\mathrm{CL}$ carried out the experiments, participated in the design and coordination of the study, and drafted the manuscript. FM participated in the design and coordination of the study and contributed to the writing of the manuscript. All authors read and approved the final manuscript.

\section{Author Details}

UCSF Helen Diller Family Comprehensive Cancer Center, University of California, San Francisco, San Francisco, CA, 94158, USA 
Received: 12 March 2010 Accepted: 8 July 2010

Published: 8 July 2010

\section{References}

1. Maddon PJ, Dalgleish AG, McDougal JS, Clapham PR, Weiss RA, Axel R: The T4 gene encodes the AIDS virus receptor and is expressed in the immune system and the brain. Cell 1986, 47:333-348.

2. Dalgleish AG, Beverley PC, Clapham PR, Crawford DH, Greaves MF, Weiss RA: The CD4 (T4) antigen is an essential component of the receptor for the AIDS retrovirus. Nature 1984, 312:763-767.

3. Choe H, Farzan M, Sun Y, Sullivan N, Rollins B, Ponath PD, Wu L, Mackay CR, LaRosa G, Newman W, et al: The beta-chemokine receptors CCR3 and CCR5 facilitate infection by primary HIV-1 isolates. Cell 1996, 85:1135-1148

4. Deng H, Liu R, Ellmeier W, Choe S, Unutmaz D, Burkhart M, Di Marzio P, Marmon S, Sutton RE, Hill CM, et al:: Identification of a major co-receptor for primary isolates of HIV-1. Nature 1996, 381:661-666.

5. Dragic T, Litwin V, Allaway GP, Martin SR, Huang Y, Nagashima KA, Cayanan C, Maddon PJ, Koup RA, Moore JP, Paxton WA: HIV-1 entry into CD4+ cells is mediated by the chemokine receptor CC-CKR-5. Nature 1996, 381:667-673.

6. Taylor BM, Foulke JS, Flinko R, Heredia A, DeVico A, Reitz M: An alteration of human immunodeficiency virus gp41 leads to reduced CCR5 dependence and CD4 independence. J Virol 2008, 82:5460-5471.

7. Jones PL, Korte T, Blumenthal R: Conformational changes in cell surface HIV-1 envelope glycoproteins are triggered by cooperation between cell surface CD4 and co-receptors. J Biol Chem 1998, 273:404-409.

8. Wickham TJ, Mathias P, Cheresh DA, Nemerow GR: Integrins alpha v beta 3 and alpha v beta 5 promote adenovirus internalization but not virus attachment. Cell 1993, 73:309-319.

9. Russell WC: Adenoviruses: update on structure and function. J Gen Virol 2009, 90:1-20

10. Zhang Y, Bergelson JM: Adenovirus receptors. J Virol 2005 79:12125-12131.

11. Fauquet CM, Mayo MA, Maniloff J, Desselberger U, Ball LA: Virus Taxonomy; Seventh Report of the International Committee of Viruses. San Diego: Academic Press; 2005.

12. Bergelson JM, Cunningham JA, Droguett G, Kurt-Jones EA, Krithivas A, Hong JS, Horwitz MS, Crowell RL, Finberg RW: Isolation of a common receptor for Coxsackie B viruses and adenoviruses 2 and 5 . Science 1997, 275:1320-1323.

13. Huang S, Kamata T, Takada Y, Ruggeri ZM, Nemerow GR: Adenovirus interaction with distinct integrins mediates separate events in cell entry and gene delivery to hematopoietic cells. J Virol 1996, 70:4502-4508.

14. Dechecchi MC, Melotti P, Bonizzato A, Santacatterina M, Chilosi M, Cabrini $G:$ Heparan sulfate glycosaminoglycans are receptors sufficient to mediate the initial binding of adenovirus types 2 and 5. J Virol 2001 75:8772-8780

15. Dechecchi MC, Tamanini A, Bonizzato A, Cabrini G: Heparan sulfate glycosaminoglycans are involved in adenovirus type 5 and 2-host cell interactions. Virology 2000, 268:382-390.

16. Adams WC, Bond E, Havenga MJ, Holterman L, Goudsmit J, Karlsson Hedestam GB, Koup RA, Lore K: Adenovirus serotype 5 infects human dendritic cells via a coxsackievirus-adenovirus receptor-independent receptor pathway mediated by lactoferrin and DC-SIGN. J Gen Virol 2009, 90:1600-1610.

17. Johansson C, Jonsson M, Marttila M, Persson D, Fan XL, Skog J, Frangsmyr $\mathrm{L}$, Wadell G, Arnberg N: Adenoviruses use lactoferrin as a bridge for CAR-independent binding to and infection of epithelial cells. J Virol 2007, 81:954-963.

18. Alemany R, Curiel DT: CAR-binding ablation does not change biodistribution and toxicity of adenoviral vectors. Gene Ther 2001 8:1347-1353.

19. Parker AL, McVey JH, Doctor JH, Lopez-Franco O, Waddington SN, Havenga MJ, Nicklin SA, Baker AH: Influence of coagulation factor zymogens on the infectivity of adenoviruses pseudotyped with fibers from subgroup D. J Virol 2007, 81:3627-3631.

20. Shayakhmetov DM, Gaggar A, Ni S, Li ZY, Lieber A: Adenovirus binding to blood factors results in liver cell infection and hepatotoxicity. J Virol 2005, 79:7478-7491.
21. Smith TA, Idamakanti N, Marshall-Neff J, Rollence ML, Wright P, Kaloss M, King L, Mech C, Dinges L, Iverson WO, et al:: Receptor interactions involved in adenoviral-mediated gene delivery after systemic administration in non-human primates. Hum Gene Ther 2003, 14:1595-1604

22. Waddington SN, McVey JH, Bhella D, Parker AL, Barker K, Atoda H, Pink R, Buckley SM, Greig JA, Denby L, et al:: Adenovirus serotype 5 hexon mediates liver gene transfer. Cell 2008, 132:397-409.

23. Waddington SN, Parker AL, Havenga M, Nicklin SA, Buckley SM, McVey JH, Baker AH: Targeting of adenovirus serotype 5 (Ad5) and 5/47 pseudotyped vectors in vivo: fundamental involvement of coagulation factors and redundancy of CAR binding by Ad5. J Virol 2007, 81:9568-9571

24. Parker AL, Waddington SN, Nicol CG, Shayakhmetov DM, Buckley SM, Denby L, Kemball-Cook G, Ni S, Lieber A, McVey JH, et al:: Multiple vitamin $\mathrm{K}$-dependent coagulation zymogens promote adenovirus-mediated gene delivery to hepatocytes. Blood 2006, 108:2554-2561.

25. Einfeld DA, Schroeder R, Roelvink PW, Lizonova A, King CR, Kovesdi I, Wickham TJ: Reducing the native tropism of adenovirus vectors requires removal of both CAR and integrin interactions. J Virol 2001 75:11284-11291

26. Leissner $P$, Legrand $V$, Schlesinger $Y$, Hadji DA, van Raaij M, Cusack S, Pavirani A, Mehtali M: Influence of adenoviral fiber mutations on viral encapsidation, infectivity and in vivo tropism. Gene Ther 2001, 8:49-57.

27. Candolfi M, Curtin JF, Xiong WD, Kroeger KM, Liu C, Rentsendorj A, Agadjanian H, Medina-Kauwe L, Palmer D, Ng P, et al:: Effective highcapacity gutless adenoviral vectors mediate transgene expression in human glioma cells. Mol Ther 2006, 14:371-381.

28. Sabichi A, Keyhani A, Tanaka N, Delacerda J, Lee IL, Zou C, Zhou JH, Benedict WF, Grossman HB: Characterization of a panel of cell lines derived from urothelial neoplasms: genetic alterations, growth in vivo and the relationship of adenoviral mediated gene transfer to coxsackie adenovirus receptor expression. J Urol 2006, 175:1133-1137.

29. Anders M, Vieth M, Rocken C, Ebert M, Pross M, Gretschel S, Schlag PM, Wiedenmann B, Kemmner W, Hocker M: Loss of the coxsackie and adenovirus receptor contributes to gastric cancer progression. $\mathrm{Br} J$ Cancer 2009, 100:352-359.

30. Jee YS, Lee SG, Lee JC, Kim MJ, Lee JJ, Kim DY, Park SW, Sung MW, Heo DS: Reduced expression of coxsackievirus and adenovirus receptor (CAR) in tumor tissue compared to normal epithelium in head and neck squamous cell carcinoma patients. Anticancer Res 2002, 22:2629-2634.

31. Li Y, Pong RC, Bergelson JM, Hall MC, Sagalowsky Al, Tseng CP, Wang Z, Hsieh JT: Loss of adenoviral receptor expression in human bladder cancer cells: a potential impact on the efficacy of gene therapy. Cancer Res 1999, 59:325-330.

32. Matsumoto K, Shariat SF, Ayala GE, Rauen KA, Lerner SP: Loss of coxsackie and adenovirus receptor expression is associated with features of aggressive bladder cancer. Urology 2005, 66:441-446.

33. Okegawa T, Li Y, Pong RC, Bergelson JM, Zhou J, Hsieh JT: The dual impact of coxsackie and adenovirus receptor expression on human prostate cancer gene therapy. Cancer Res 2000, 60:5031-5036.

34. Rauen KA, Sudilovsky D, Le JL, Chew KL, Hann B, Weinberg V, Schmitt LD, McCormick F: Expression of the coxsackie adenovirus receptor in normal prostate and in primary and metastatic prostate carcinoma: potential relevance to gene therapy. Cancer Res 2002, 62:3812-3818.

35. Anders M, Christian C, McMahon M, McCormick F, Korn WM: Inhibition of the Raf/MEK/ERK pathway up-regulates expression of the coxsackievirus and adenovirus receptor in cancer cells. Cancer Res 2003, 63:2088-2095

36. Anders M, Hansen R, Ding RX, Rauen KA, Bissell MJ, Korn WM: Disruption of $3 \mathrm{D}$ tissue integrity facilitates adenovirus infection by deregulating the coxsackievirus and adenovirus receptor. Proc Natl Acad Sci USA 2003, 100:1943-1948.

37. Philipson L, Lonberg-Holm K, Pettersson U: Virus-receptor interaction in an adenovirus system. J Virol 1968, 2:1064-1075.

38. Hynes RO: Integrins: versatility, modulation, and signaling in cell adhesion. Cell 1992, 69:11-25.

39. Stewart PL, Nemerow GR: Cell integrins: commonly used receptors for diverse viral pathogens. Trends Microbiol 2007, 15:500-507.

40. Feire AL, Koss H, Compton T: Cellular integrins function as entry receptors for human cytomegalovirus via a highly conserved disintegrin-like domain. Proc Natl Acad Sci USA 2004, 101:15470-15475. 
41. Gavrilovskaya IN, Shepley M, Shaw R, Ginsberg MH, Mackow ER: beta3 Integrins mediate the cellular entry of hantaviruses that cause respiratory failure. Proc Natl Acad Sci USA 1998, 95:7074-7079.

42. Hewish MJ, Takada Y, Coulson BS: Integrins alpha2beta1 and alpha4beta 1 can mediate $S A 11$ rotavirus attachment and entry into cells. J Virol 2000, 74:228-236

43. Miyamoto S, Akiyama SK, Yamada KM: Synergistic roles for receptor occupancy and aggregation in integrin transmembrane function. Science 1995, 267:883-885

44. Chiu CY, Mathias P, Nemerow GR, Stewart PL: Structure of adenovirus complexed with its internalization receptor, alphavbeta5 integrin. Virol 1999, 73:6759-6768.

45. Salone B, Martina Y, Piersanti S, Cundari E, Cherubini G, Franqueville L, Failla CM, Boulanger P, Saggio I: Integrin alpha3beta1 is an alternative cellular receptor for adenovirus serotype 5. J Virol 2003, 77:13448-13454.

46. Humphries JD, Byron A, Humphries MJ: Integrin ligands at a glance. J Cell Sci 2006, 119:3901-3903.

47. Li E, Brown SL, Stupack DG, Puente XS, Cheresh DA, Nemerow GR: Integrin alpha(v)beta1 is an adenovirus coreceptor. J Virol 2001, 75:5405-5409.

48. Mathews JC: Fundamentals of Receptor, Enzyme, and Transport Kinetics. Boca Raton: CRC Press; 1993.

49. Tsibris AM, Kuritzkes DR: Chemokine antagonists as therapeutics: focus on HIV-1. Annu Rev Med 2007, 58:445-459.

50. Bhattacharya J, Peters PJ, Clapham PR: CD4-independent infection of HIV and SIV: implications for envelope conformation and cell tropism in vivo. Aids 2003, 17(Suppl 4):S35-43.

51. Law LK, Davidson BL: What does it take to bind CAR? Mol Ther 2005, 12:599-609.

52. Wang $X$, Bergelson JM: Coxsackievirus and adenovirus receptor cytoplasmic and transmembrane domains are not essential for coxsackievirus and adenovirus infection. J Virol 1999, 73:2559-2562.

53. Lortat-Jacob H, Chouin E, Cusack S, van Raaij MJ: Kinetic analysis of adenovirus fiber binding to its receptor reveals an avidity mechanism for trimeric receptor-ligand interactions. J Biol Chem 2001, 276:9009-9015

54. Walters RW, Freimuth P, Moninger TO, Ganske I, Zabner J, Welsh MJ: Adenovirus fiber disrupts CAR-mediated intercellular adhesion allowing virus escape. Cell 2002, 110:789-799.

55. Farmer C, Morton PE, Snippe M, Santis G, Parsons M: Coxsackie adenovirus receptor (CAR) regulates integrin function through activation of p44/42 MAPK. Exp Cell Res 2009, 315:2637-2647.

56. Roelvink PW, Kovesdi I, Wickham TJ: Comparative analysis of adenovirus fiber-cell interaction: adenovirus type $2(\mathrm{Ad} 2)$ and Ad9 utilize the same cellular fiber receptor but use different binding strategies for attachment. J Virol 1996, 70:7614-7621.

57. Lopez S, Arias CF: Multistep entry of rotavirus into cells: a Versaillesque dance. Trends Microbiol 2004, 12:271-278.

58. Ludert JE, Mason BB, Angel J, Tang B, Hoshino Y, Feng N, Vo PT, Mackow EM, Ruggeri FM, Greenberg HB: Identification of mutations in the rotavirus protein VP4 that alter sialic-acid-dependent infection. J Gen Virol 1998, 79(Pt 4):725-729.

59. Mendez E, Arias CF, Lopez S: Binding to sialic acids is not an essential step for the entry of animal rotaviruses to epithelial cells in culture. Virol 1993, 67:5253-5259.

60. Edelstein ML, Abedi MR, Wixon J, Edelstein RM: Gene therapy clinical trials worldwide 1989-2004-an overview. J Gene Med 2004, 6:597-602

61. Carriero MV, Del Vecchio S, Capozzoli M, Franco P, Fontana L, Zannetti A Botti G, D'Aiuto G, Salvatore M, Stoppelli MP: Urokinase receptor interacts with alpha(v)beta5 vitronectin receptor, promoting urokinasedependent cell migration in breast cancer. Cancer Res 1999, 59:5307-5314

62. Gladson CL, Dennis C, Rotolo TC, Kelly DR, Grammer JR: Vitronectin expression in differentiating neuroblastic tumors: integrin alpha $v$ beta 5 mediates vitronectin-dependent adhesion of retinoic-aciddifferentiated neuroblastoma cells. Am J Pathol 1997, 150:1631-1646.

63. Carlisle RC, Di Y, Cerny AM, Sonnen AF, Sim RB, Green NK, Subr V, Ulbrich K, Gilbert RJ, Fisher KD, et al: Human erythrocytes bind and inactivate type 5 adenovirus by presenting Coxsackie virus-adenovirus receptor and complement receptor 1. Blood 2009, 113:1909-1918.

64. Seiradake E, Henaff D, Wodrich H, Billet O, Perreau M, Hippert C, Mennechet F, Schoehn G, Lortat-Jacob H, Dreja H, et al:: The cell adhesion molecule "CAR" and sialic acid on human erythrocytes influence adenovirus in vivo biodistribution. PLoS Pathog 2009, 5:e1000277.

65. Wang Y, Gangeswaran R, Zhao X, Wang P, Tysome J, Bhakta V, Yuan M, Chikkanna-Gowda CP, Jiang G, Gao D, et al.: CEACAM6 attenuates adenovirus infection by antagonizing viral trafficking in cancer cells. J Clin Invest 2009, 119:1604-1615.

66. Krougliak V, Graham FL: Development of cell lines capable of complementing E1, E4, and protein IX defective adenovirus type 5 mutants. Hum Gene Ther 1995, 6:1575-1586.

67. Tollefson AE, Hermiston TW, Wold WSM: Preparation and titration of $\mathrm{CsCl}$-banded adenovirus stock. Methods in Molecular Medicine 1998, 20:1.

68. Johnson L, Shen A, Boyle L, Kunich J, Pandey K, Lemmon M, Hermiston T, Giedlin M, McCormick F, Fattaey A: Selectively replicating adenoviruses targeting deregulated E2F activity are potent, systemic antitumor agents. Cancer Cell 2002, 1:325-337.

doi: $10.1186 / 1743-422 X-7-148$

Cite this article as: Lyle and McCormick, Integrin ?v?5 is a primary recepto for adenovirus in CAR-negative cells Virology Journal 2010, 7:148

\section{Submit your next manuscript to BioMed Central and take full advantage of:}

- Convenient online submission

- Thorough peer review

- No space constraints or color figure charges

- Immediate publication on acceptance

- Inclusion in PubMed, CAS, Scopus and Google Scholar

- Research which is freely available for redistribution

Submit your manuscript at www.biomedcentral.com/submit
C) Biomed Central 